Annals of Tropical Research 31[1]90-101(2009)

(c) VSU, Leyte, Philippines

\title{
Nutrient characteristics of aggregates and rhizosphere of a degraded upland soil: Implication for soil fertility evaluation
}

\author{
Ian A. Navarrete ${ }^{1,2}$, Salfe O. Macalde', and Victor B. Asio ${ }^{1}$ \\ ${ }^{1}$ Department of Agronomy and Soil Science, Visayas State University, \\ Baybay, Leyte 6521-A, Philippines; \\ ${ }^{2}$ United Graduate School of Agricultural Sciences, Iwate University, \\ Iwate 020-8555, Japan
}

\begin{abstract}
The influence of aggregates and rhizosphere on nutrient availability of degraded tropical soils is not yet well understood. The study evaluated differences in the nutrient characteristics between rhizosphere and non-rhizosphere soils, aggregated and homogenized soil samples, and inner and outer portions of aggregates. Soil samples were collected from a degraded upland soil in Pinabacdao, Samar, Philippines, and analyzed for selected soil properties. Results revealed that rhizosphere soil had higher organic matter (OM), available P contents, and exchangeable $\mathrm{Ca}$ and $\mathrm{Mg}$ contents than the non-rhizosphere soil but with no considerable variation in soil $\mathrm{pH}$. Results also showed no differences in the chemical properties between the outer and inner portions of aggregates and that the aggregated samples slightly differed from the homogenized soil samples in terms of some chemical characteristics. Findings suggest that the standard practice of homogenizing soil sample for analysis may have limitations for fertility evaluation of degraded soils.
\end{abstract}

Keywords: degraded soil, soil aggregates, rhizosphere soil, soil fertility evaluation

Correspondence: I.A. Navarrete. Present Address: United Graduate School of Agricultural Sciences, Iwate University, Iwate 020-8555, Japan. E-mail: ian-navarrete@daad-alumni.de DOI: $10.32945 / \operatorname{atr} 3115.2009$ 


\section{INTRODUCTION}

The common way of evaluating soil fertility in agriculture is through routine soil chemical analysis. Although this method is widely used, it has received increasing criticism in recent years because of the difficulty of interpreting the results (Landon, 1991; Marschner, 1995), and the often poor correlation between results of soil analysis and the nutrient uptake of many crops (Fernandez, 1992; Marschner, 1995). One reason is the diversity of extracting solutions since plant nutrient availability is defined mainly by the use of chemical extracting solutions that are often prone to analytical errors (Gregory, 2005). Another reason is the use of the fineearth fraction (i.e. homogenized sample) in the laboratory analysis. Soil homogenization, the international standard of preparing soil samples for laboratory analysis, requires the mechanical destruction of aggregates into the smaller microaggregates and then passing them through a $2 \mathrm{~mm}$ sieve. This process disturbs the natural aggregates and the soil particles inside the aggregates that do not participate in the nutrient dynamics (e.g. interior aggregates) in the field are exposed thereby changing the chemical composition and behavior of the sample.

Mineral nutrients that plants obtain from the soil pass through the surface of aggregates and the thin layer of soil close to the roots, termed as "rhizosphere" (e.g. Horn, 1987 and 1989; Marschner, 1995). As plant roots grow through the soil, the addition of root exudates, mucilages, and lysates contribute to the biochemical processes that occur in the vicinity of the root system (Gisi, 1990; Hinsinger et al., 2005; Gregory, 2005), which in turn directly influence plant growth. Consequently, since the aggregates and rhizosphere participate directly in the soil nutrient dynamics, the use of homogenized sample for soil analysis needs a second look (Marschner, 1995).

Widespread soil degradation is a major agricultural and environmental problem in the Philippines (Asio, 1997; Navarrete and Tsutsuki, 2008; Navarrete et al., 2009). The problem is closely related to the rapid increase in population in the last 50 years which has resulted in the cultivation of upland and forested areas. Until now few studies have been conducted dealing with the characteristics and fertility status of 
degraded soils in the Philippines. Thus there is a need to understand these problem soils because they are important resources for food and diesel plant production.

This study aimed to evaluate differences in the nutrient characteristics between rhizosphere and non-rhizosphere soils, aggregated and homogenized soil samples, and inner and outer portions of aggregates. It also tested our hypothesis that the standard practice of preparing soil sample by homogenization changes the nutrient characteristics of the soil samples.

\section{MATERIALS AND METHODS}

\section{Study area}

The study was conducted in ca. $2000 \mathrm{~m}^{2}$ undulating field in Pinabacdao, Western Samar, Philippines (Fig. 1). This area is one of the most highly degraded uplands in Central Philippines (Asio, 1998), which can be attributed to the long history of unsuitable land-uses (Navarrete $e t$ al., 2000). Geologically, the area is underlain by sedimentary rocks particularly sandstone ranging in age from Upper Miocene to Pliocene (Simon et al., 1975). The soil is well-developed, reddish, acidic, and belongs to Ultisols (USDA Soil Taxonomy) or Acrisols (FAO System) and based from the estimates of Navarrete et al. (2007), it occupies about $24 \%$ of the total land area of Samar. The soil is typically severely eroded and very compact with a bulk density of $>1.25 \mathrm{~g} \mathrm{~cm}^{-3}$ (Navarrete et al., 2000) suggesting its degraded nature. Average annual temperature and rainfall are $27^{\circ} \mathrm{C}$ and $1500-2500 \mathrm{~mm}$, respectively. The area has been rotationally grown to sweetpotato (Ipomoea batatas), corn (Zea mays), and taro (Colocasia esculenta), which are planted along the hedgerows of vetiver grass (Vetiveria zizanoides). Cogon (Imperata cylindrica) and talahib (Saccharum spontaneum) are the dominant grasses, whereas patches of wild guava (Psidium guajava), and native trees species are found in the upper slope. Asio (1997 and 1998) observed cogon, talahib and wild guava as indicators of degraded soil condition. 


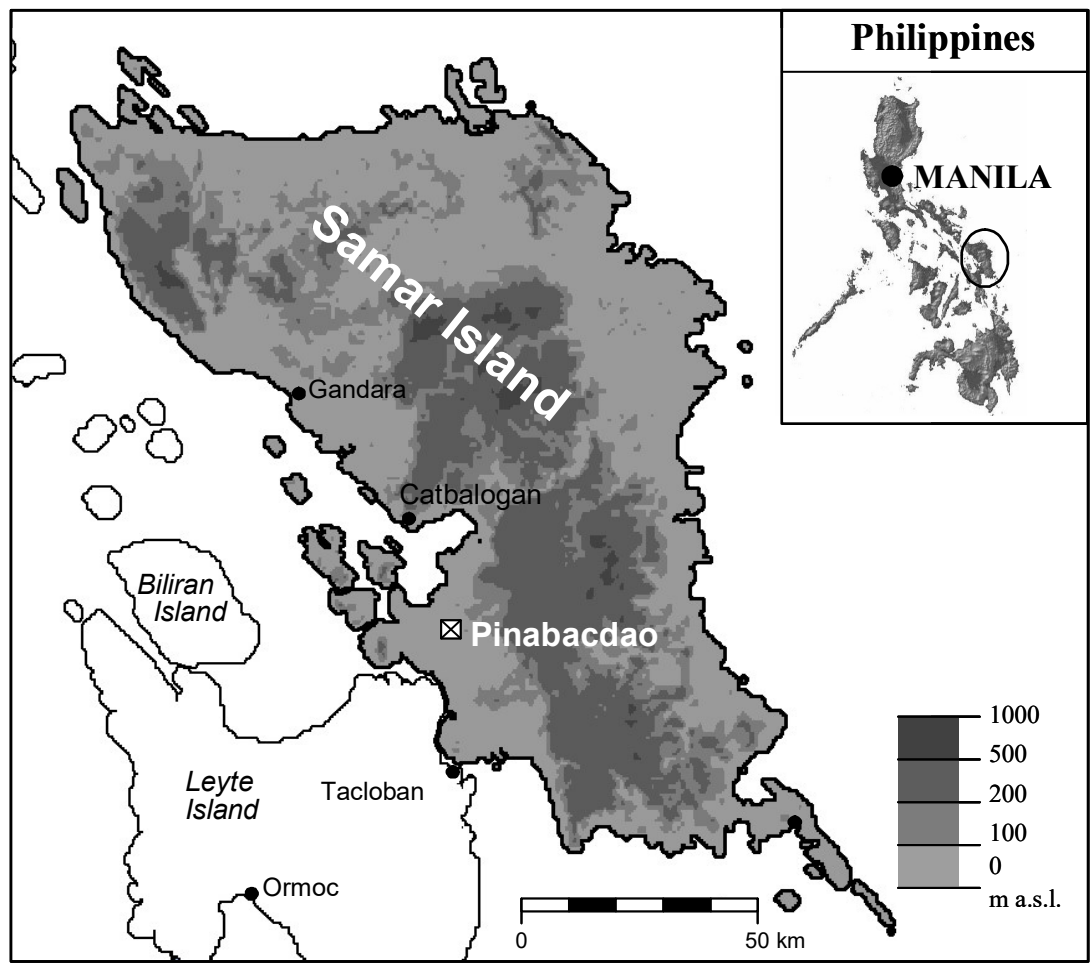

Figure 1. Map of Samar and the location of the study area (marked X) 


\section{Collection of rhizosphere and non-rhizosphere soil}

To compare the chemical characteristics of rhizosphere and nonrhizosphere soils, nine vetiver plants were randomly selected and uprooted. Vetiver grass was used as sample plant since it grows well in the area despite the severe soil physical and chemical degradations. The root volume of each uprooted vetiver plant corresponded to ca. $0.01 \mathrm{~m}^{3}$ soil materials (approximately $10 \mathrm{~cm}$ depth), which were cut and extracted around a vetiver grass clump. Right after being uprooted, the living roots were carefully shaken and the soil material that fell into the container was regarded as the non-rhizosphere soil, while the one adhering into the roots ( $<3 \mathrm{~mm}$ thick) after they had been shaken was considered as the rhizosphere soil. The rhizosphere soil was carefully collected by gently brushing the roots using a paint brush and was then air-dried. The separation of the rhizosphere soil and non-rhizosphere soil was done following the method outlined by Courchesne and Gobran (1997). A representative sample of the typical degraded soil away from the vetiver plants was also collected.

\section{Collection and separation of soil aggregate layers}

Ten sampling points were randomly selected in the study site. In each sampling point, five sub-samples were collected and composited from the surface as well as from the sub-surface horizons. To minimize disturbance of the aggregates after sampling and during transport to the laboratory, the soil samples were carefully placed in buckets and were immediately air-dried in the laboratory. From the air-dried undisturbed aggregates, about 50 natural aggregates per sample were collected and mechanically separated into the exterior and interior portions following the method described by Horn (1987). In separating the soil aggregate layers, the exterior portion (ca. 2-3 mm thick) was scrapped carefully by using a razor blade and the remaining part was considered as the interior portion (Horn, 1987). To prepare the homogenized and natural aggregates, enough soil from each of the air-dried samples was taken and divided into two parts. One part was ground to pass a $2 \mathrm{~mm}$ sieve to represent the 
homogenized sample (i.e. fine-earth fraction), whereas the second part was fractionated by dry-sieving into different aggregate sizes (e.g. $<1$ $\mathrm{mm}, 1-2 \mathrm{~mm}, 2-4 \mathrm{~mm}$ ). Dry sieving was adapted to ensure that less chemical disturbance of aggregates, which were to be analyzed for nutrient content because wet sieving often results in the removal and dissolution of nutrients adsorbed on the surface of soil aggregates.

\section{Laboratory analyses}

Particle size distribution of air-dried aggregates of different size classes $(<1 \mathrm{~mm}, 1-2 \mathrm{~mm}, 2-4 \mathrm{~mm})$ as well as of the homogenized $(<2$ $\mathrm{mm}$ ) soil samples was determined by pipette method (ISRIC, 1995). Soil $\mathrm{pH}\left(\mathrm{H}_{2} \mathrm{O}\right)$ was measured using a glass electrode in the supernatant of a 1:2.5 soil/water ratio; organic matter (OM) content by Walkley-Black method (ISRIC, 1995); available P by the method of ISRIC (1995), and exchangeable $\mathrm{Ca}$ and $\mathrm{K}$ by extraction using unbuffered $1 \mathrm{M} \mathrm{NH}_{4} \mathrm{Cl}$ (Schlichting et al., 1995) and quantification by atomic absorption spectrophotometry (AAS).

\section{RESULTS AND DISCUSSION}

\section{Differences between rhizosphere and non-rhizosphere soils}

Selected chemical properties of the rhizosphere and non-rhizosphere soils are presented in Table 1 . As can be seen, soil pH did not vary among the rhizosphere soil, non-rhizosphere soil, and the typical degraded soil (not affected by vetiver plants) in the site. In contrast, the OM content significantly varied among the rhizosphere soil, non-rhizosphere soil and the typical degraded soil. The rhizosphere soil gave the highest OM content (Table 1) which can be due to the process called rhizodeposition, the release of organic $\mathrm{C}$ from decaying roots and various root exudates into the rhizosphere. Rhizodeposition is important because of the physical and biochemical role of SOM particularly in degraded soils (Navarrete and Tsutsuki, 2008; Sanchez, 1976). Available P content was higher in the soil influenced by vetiver plant than in the typical degraded soil and 


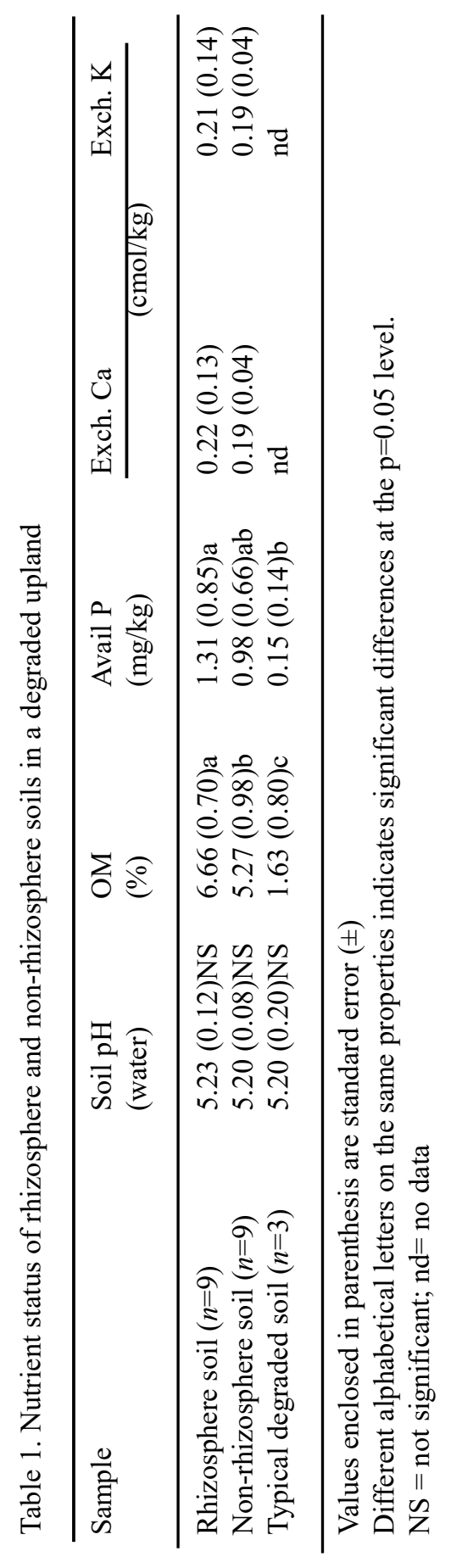


the difference was greatest between the rhizosphere and the soil not affected by the vetiver (typical degraded soil) (Table 1). This suggests that rhizosphere processes enhance $P$ availability (Gisi, 1990; Marschner, 1995; Gregory, 2005; Hinsinger et al., 2005). Another reason is the contribution of OM to higher available $\mathrm{P}$ as indicated by the high significant positive correlation between $\mathrm{OM}$ and available $\mathrm{P}(\mathrm{r}=0.67$; $\mathrm{p}<0.001 ; \mathrm{n}=21$ ). Although there was a significant difference in the amount of available $\mathrm{P}$ between the rhizosphere soil and non-vetiver soil, the available P level was still much lower than the sufficient level for plant growth (8-15 mg/kg; Landon, 1991). The very low available P in the soil can be explained by the nature of the parent material (i.e. sandstone), which has very low inherent $\mathrm{P}$ and by the acidic nature of the soil. Exchangeable $\mathrm{Ca}$ and $\mathrm{Mg}$ contents were slightly higher in the rhizosphere soil compared to the non-rhizosphere soil although this was not statistically different. Hendricks and Jungk (1981) found a $25 \%$ higher amount of exchangeable $\mathrm{Ca}$ in the rhizosphere soil than in the nonrhizosphere soil of wheat. Such effects can be due to the organic acids produced by roots which increase the solubility of exchangeable bases in the rhizosphere soil (Jones and Brassington, 1998).

\section{Nutrient characteristics of soil aggregates}

Tables 2 and 3 show selected physico-chemical characteristics of the interior and exterior portions of aggregates, different aggregate size classes, and homogenized sample of the degraded soil. As can be seen, the soil was dominated by silt and clay with low sand content, implying a strongly weathered condition of the soil (classified as Ultisol in the Soil Taxonomy or Acrisol in the FAO System). In both the surface and subsurface soils, the exterior and interior portions of the aggregates had comparable clay content but tended to be slightly higher than the homogenized sample in the surface horizon. Larger aggregates (e.g. 2 to $4 \mathrm{~mm}$ ) had more clay content than smaller aggregates $(<1 \mathrm{~mm})$.

While $\mathrm{pH}$ was comparable among the interior aggregate portion, exterior aggregate portion, and homogenized sample, the trend was different for the aggregate size classes. Larger aggregates tended to have slightly higher $\mathrm{pH}$ values compared with smaller aggregates and with the 


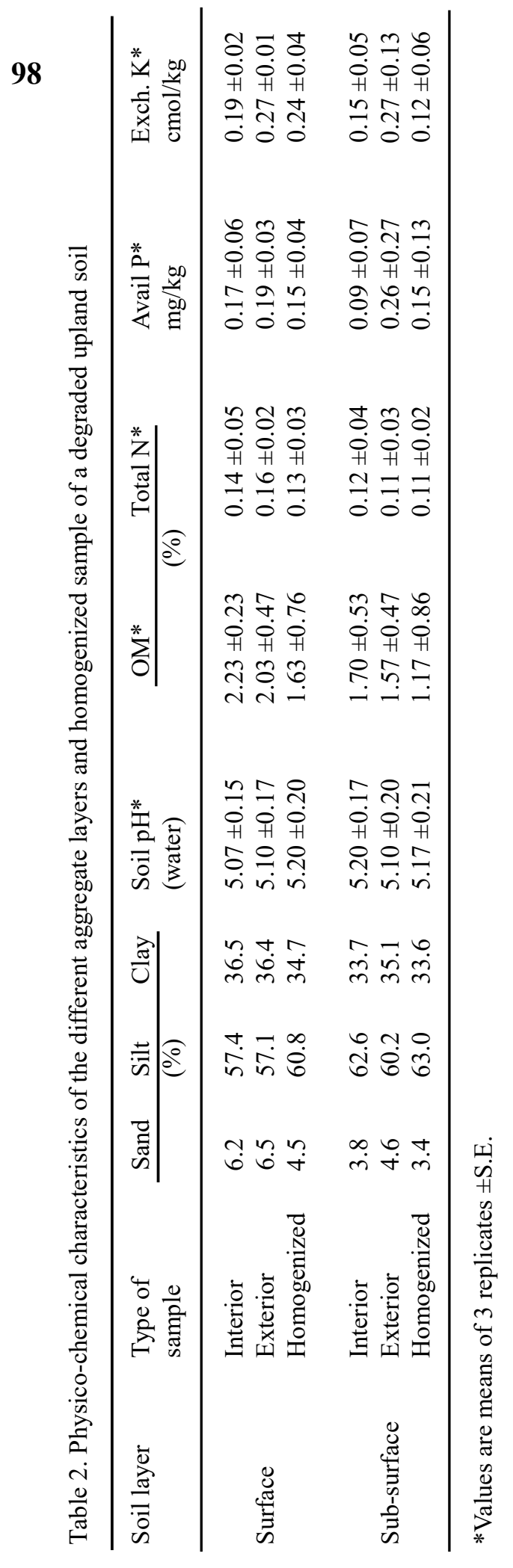

Navarrete et al. 


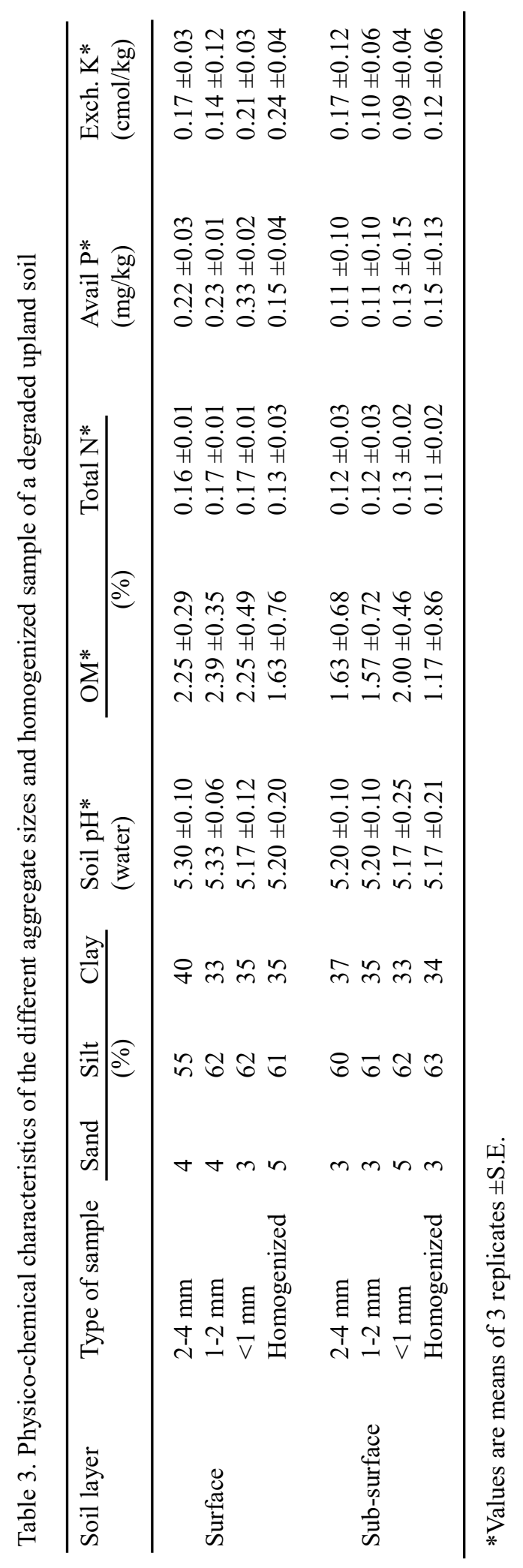


homogenized sample implying that the larger aggregates may enhance higher nutrient availability. Organic matter contents did not vary among the different aggregate size classes but tended to be slightly higher than the homogenized samples. Results also showed no clear differences in the available $P$ and exchangeable $K$ contents between interior and exterior portions of aggregates and among aggregate classes.

The study indicates that nutrient characteristics vary between rhizosphere soil and non-rhizosphere soil as well as between natural soil aggregates and homogenized sample of the degraded soil studied. The findings imply that the conventional method of using homogenized sample has limitations for fertility evaluation of degraded soils.

\section{REFERENCES}

ASIO, V.B. 1997. A review of upland agriculture, population pressure, and environmental degradation in the Philippines. Annals of Tropical Research. 19: 1-18.

ASIO, V.B. 1998. Degraded upland soils in the Philippines: research needs. PLITS, Stuttgart. 16 (2): 275-278.

COURCHESNE, F. and G.R. GOBRAN. 1997. Mineralogical variation of bulk and rhizosphere soil away from a Norway spruce stand. Soil Science Society of American Journal. 61: 1245-1249.

FERNANDEZ, A.O. 1992. Relationship between nutrient concentration in crop tissue and acid soil. B.Sc. Thesis, ViSCA, Baybay, Leyte, 42 pp.

GREGORY, P.J. 2005. Roots, rhizosphere and soil: the route to a better understanding of soil science?. European Journal of Soil Science. 57: 2-12.

GISI, U. 1990. Soil Ecology. Geor Thimer Verlag, Stuttgart, 304 pp (in German).

HENDRICKS, L. and K. JUNGK. 1981. Estimation of the nutrient distribution around plant roots by separate analysis of rhizo and bulk soil. Journal of Soil Science and Plant Nutrition. 144: 276-282 (in German with English abstract)

HINSINGER, P., G.R. GOBRAN, P.J.GREGORY and W.W. WENZEL. 2005. Rhizosphere geometry and heterogeneity arising from root-mediated physical and chemical processes. New Phytologist. 168: 293-303.

HORN, R. 1987. The role of structure for nutrient sorptivity of soil. Journal of Soil Science and Plant Nutrition. 150: 13-16 (in German with English abstract). 
HORN, R. 1989. The importance of soil structure for the nutrient availability. KaliBriefe (Büntehof). 19: 505-515.

INTERNATIONAL SOIL REFERENCE AND INFORMATION CENTER. 1995. Procedures for Soil Analysis (L.P. van Reeuwijk, Ed). Wageningen, The Netherlands, 106 pp.

JONES, D.L. and D.S. BRASSINGTON. 1998. Sorption of organic acids in acid soil and its implication in the rhizosphere. European Journal of Soil Science. 49: 447-448.

LANDON, J.R. (ed.). 1991. Booker Tropical Soil Manual. Longman Scientific and Technical, Harlow, England. 340 pp.

MARSCHNER, H. 1995. Mineral Nutrition in Higher Plants. 2nd edn. Academic Press, London.

NAVARRETE, I.A., V. B. ASIO, E. BALBARINO and A. TULIN. 2000. The physicochemical properties of rhizosphere soil grown to vetiver in a degraded upland. Grassland Society of the Philippine Journal. 4 (1): 29-34.

NAVARRETE I.A., V.B. ASIO, R. JAHN and K. TSUTSUKI. 2007. Characteristics and genesis of two strongly weathered soils in Samar, Philippines. Australian Journal of Soil Research. 45: 153-163.

NAVARRETE, I.A. and K. TSUTSUKI. 2008. Land-use impact on soil carbon, nitrogen, neutral sugar composition and related chemical properties in a degraded Ultisol derived from volcanic materials in Leyte, Philippines. Soil Science and Plant Nutrition. 54: 321-331.

NAVARRETE, I.A., K. TSUTSUKI, V.B. ASIO and R. KONDO. 2009. Characteristics and formation of rain forest soils derived from late Quaternary basaltic rocks in Leyte, Philippines. Environmental Geology 58-1257-1268.

SANCHEZ, P.A. 1976. Properties and Management of Soils in the Tropics. Wiley, New York, 618 pp.

SCHLICHTING, E., H.P. BLUME and K. STAHR. 1995. Bodenkundliches Practikum. 2nd edn. Blackwell, Berlin, 295 pp.

SIMON, J.D., N.M. NATIVIDAD, R.M. AAMABA and T.P. DEMEN. 1975. Soil Survey of Samar Provinces, Philippines. Bureau of Prints, Manila. 